\title{
Achievement Motivation as an Internal Factor of Student's Personality Development
}

\author{
Olga Tapalova \\ Kiev National University named after Shevchenko, Ukraine
}

\begin{abstract}
This article presents the results of scientific studies on achievement motivation and selfactualization features among students of humanitarian and economic specialties in the learning process. Analysis of these results shows that the optimal level of achievement motivation increases the level of self-actualization. Students with a strong achievement motivation tend to reveal and develop personal potential.

The significance of this study is that the revealed interrelations between achievement motivation and self-actualization level of students allows us to conclude that a high level of achievement motivation is a stimulus for students' self-actualization.
\end{abstract}

\section{Introduction}

Achievement motivation is a stable disposition, which is shown in an aspiration to implement meaningful activities to human in the best degree. Such aspiration of individual intensifies the disclosure of the personality's best features. Achievement motivation is linked to the man's desire to maintain the best achieved results at a high level [1]. Achievement motivation occupies a leading position in the personality structure and serves as a basic concept for explaining the behavior of the driving forces.

The aim of our study was to investigate achievement motivation and self-actualization features of students of humanitarian and economics specialties.

Objectives of the study:

1. Identifying the level and characteristics of the students' self-actualization.

2. Psychodiagnostic of motivational structure of the students' personality.

3. Study of achievement motivation among students.

\section{Literature Review}

H. Heckhausen considers that to increase or maintain the highest possible human ability to all types' of activities it is necessary to have achievement motivation, which explains the focus of action.
Motivation effects on how and in what direction functional resources and abilities of the person, his interests and aspirations will be used [2].

G. Murray assigns a special role to the needs to achieve, which is treated as an overcoming obstacles, achieving high standards, competition and superiority over others, effort and victory. Murray called the achievement motivation - a generalized need [3]

D. McClelland considers the achievement motivation as a steadily manifested need of individual to succeed in a variety of activities, free from the socio-historical conditions as the root cause of human behavior. In this case it is concluded that the success of economic development of society depends on "national level" of motive to achieve success [4].

D. Ushakov believes that the achievement motivation is a suitable candidate for the role of strict, but fair mentor of abilities. There are two ways of such influence: the first - people that are more motivated by achievement should work harder to improve their abilities, carry out intellectual training more often; the second - advantages of more motivated examinees may appear in the process of intellectual activity, particularly in testing where they will show superior results. This implies that increase of intelligence should be expected from the people, who are more motivated by achievement [5].

M. Magomed-Eminov considers the achievement motivation as a functional system of together integrated affective and cognitive processes that regulate the process of working in a situation of achievement throughout the course of its implementation [6, 7].

Self-actualization in modern science is understood as a conscious human activities aimed at the maximum possible disclosure and use of his potential for the benefit of society and himself. Currently more common is "syncretic" model of human behavior, showing its merger with the mass phenomena in culture. That is why today motivation for self-realization, self-actualization in society is especially important. The concept of selfactualization is based on a theory of motivation developed by Maslow, which suggests that the system of human motivation has the form of hierarchically ordered system in which the value of self-actualization becomes the highest purpose in life, the meaning of human life [8]. 


\section{Experimental base}

Students of Kazakh National Pedagogical University named after Abay and Kazakh Academy of Labour and Social Affairs in Almaty had participated in the research.

The selection for the first group included students of humanities - psychologists of $2^{\text {nd }}$ and $3^{\text {rd }}$ courses. The selection for the second group included students of economics - managers of $2^{\text {nd }}$ and $3^{\text {rd }}$ courses. Total number of examinees was 60 people, each group consisted from 30 students (35 male and 25 female). Age of respondents -17 to 22 years. Period of the pilot study covers $2011-2013$ years. The survey was carried out on a voluntary basis in the group form.

\section{Research methods.}

1. Personality questionnaire for the selfactualization diagnostics "SAMOAL" (modification of POI questionnaire by N. Kalina and A. Lazukin, created by E. Snowstorm) [9].

2. "Diagnostics of personality's motivational structure" methodology by V. Milman [10].

3. The method of achievement motivation diagnostics by A. Mehrabian's modified by $\mathrm{M}$. Magomed-Eminov [7].

Using self-actualization diagnostics "SAMOAL" we identified the level and peculiarities of selfactualization, along with the behavioral component of consciousness of studied personality. Examinees were asked 100 paired statements, from which they had to choose one, spread over 11 scales.

Use of "Diagnostics of personality's motivational structure" methodology by V. Milman identified some consistent trends of students' personality. Such as - total activity, communication, social status, comfort.

By analyzing responses of students we identified working and daily motivational orientation of the student's personality. According to the instructions of this methodology, we have offered students 14 statements concerning the life and aspirations of certain aspects of a person's lifestyle. Examinees had to express their attitude to them for each of the 8 different answers in the affirmative or negative.

The method of achievement motivation diagnostics by A. Mehrabian's modified by $M$. Magomed-Eminov intended to diagnose two generalized stable motives of personality: motive of striving towards success and motive of avoiding failure. The method evaluates which of these two motives dominates. Test represents a questionnaire that has two forms - male (form A) and female (Form B).

Students received the stimulus material, given a certain time. The obtained results have been processed. For each answer the student gets a certain number of points. Scoring was carried out using a keys and simple summation.

Statistical analysis was performed using correlation, factor analysis; the Mann-Whitney (U) test was used.

\section{Results and Discussion}

There are average values that have been obtained in the result of research of level and characteristics of the students' self-actualization are shown in Table 1.

Table 1. Features of the self-actualization of examined students

\begin{tabular}{|c|c|c|c|c|c|}
\hline \multirow{2}{*}{$\begin{array}{c}\text { Sca- } \\
\text { le }\end{array}$} & \multicolumn{2}{|c|}{$\mathrm{GP}(\mathrm{n}=30)$} & \multicolumn{2}{|c|}{$\mathrm{FM}(\mathrm{n}=30)$} & $\mathrm{U}$ \\
\cline { 2 - 6 } Tom & $\sigma$ & $\mathrm{M} \pm \mathrm{m}$ & $\sigma$ & \\
\hline TO & $\begin{array}{c}12 \pm \\
1,56\end{array}$ & 5,42 & $\begin{array}{c}13 \pm \\
1,42\end{array}$ & 7,00 & 9786 \\
\hline $\mathrm{V}$ & $\begin{array}{c}13 \pm \\
1,55\end{array}$ & 5,41 & $\begin{array}{c}12 \pm \\
1,37\end{array}$ & 5,67 & 9846 \\
\hline VHN & $\begin{array}{c}15 \pm \\
1,48\end{array}$ & 4,32 & $\begin{array}{c}11 \pm \\
1,31\end{array}$ & 6,78 & 8846 \\
\hline NC & $\begin{array}{c}13 \pm \\
1,64\end{array}$ & 4,56 & $\begin{array}{c}13 \pm \\
1,56\end{array}$ & 6,22 & $\begin{array}{c}1009 \\
8\end{array}$ \\
\hline C & $\begin{array}{c}12 \pm \\
1,23\end{array}$ & 4,76 & $\begin{array}{c}14 \pm \\
1,88\end{array}$ & 5,33 & 8796 \\
\hline A & $\begin{array}{c}12 \pm \\
1,63\end{array}$ & 5,67 & $\begin{array}{c}12 \pm \\
1,67\end{array}$ & 5,09 & $\begin{array}{c}1092 \\
7\end{array}$ \\
\hline S & $\begin{array}{c}13 \pm \\
1,54\end{array}$ & 5,28 & $\begin{array}{c}11 \pm \\
1,89\end{array}$ & 7,67 & 9678 \\
\hline SU & $\begin{array}{c}13 \pm \\
1,60\end{array}$ & 5,56 & $\begin{array}{c}10 \pm \\
1,35\end{array}$ & 7,05 & 9893 \\
\hline AS & $\begin{array}{c}12 \pm \\
1,60\end{array}$ & 7,03 & $\begin{array}{c}12 \pm \\
1,45\end{array}$ & 6,28 & 8845 \\
\hline S & $\begin{array}{c}15 \pm \\
1,59\end{array}$ & 7,45 & $\begin{array}{c}15 \pm \\
1,78\end{array}$ & 4,45 & 2678 \\
\hline FC & $\begin{array}{c}14 \pm \\
1,60\end{array}$ & 6,03 & $\begin{array}{c}15 \pm \\
1,98\end{array}$ & 3,67 & 9765 \\
\hline
\end{tabular}

Note: GP - a group of psychologists; GM - a group of managers; $\mathrm{M} \pm \mathrm{m}$ - mean \pm standard deviation; $\sigma$ median; $U$ - the Mann-Whitney test; TO - time orientation; V - values; VHN - view of human nature; NC - need for cognition; C - creativity; A - autonomy; $S$ - spontaneity; SU - self-understanding; AS autosympathy; S - sociability; FC - flexibility in communication.

Both groups showed equally good results according to the index of "time orientation" (12 and 13). This suggests that students try to live in the present, they are well aware of the existential value of life "here and now", enjoy the present moment. "Value" index is at the same level for psychologists and managers almost (13 and 12). The data obtained indicate that examined, students tend to become selfactualizing person. Values such as truth, goodness, beauty, integrity, lack of double standards, the procedure for them are very valuable. Poor results on this scale indicate the absence of established values 
or presence of disappointment, about the lack of interest. Averages on a scale of "view of human nature" were high for students of psychology (15), for managers are much lower (11). High scores indicate that students in the humanities believe in the strength and power of people and it is the basis for establishing sincere and harmonious interpersonal relationships. Lower results from students of economics have shown differences against trust in people, which explains the difficulties in communicating with people, deny of person's ability to a harmonious relationship built on mutual respect, honesty and sincerity. Indicators in terms of "need for cognition" showed the same mean (13/13). The data demonstrate the desire of students to selfactualization, testify openness to new knowledge. On a scale of "creativity" scores were higher among managers (14), which show the creative attitude towards life. On a scale of "autonomy", both groups showed similar mean scores as a result of testing $(12 / 12)$. The scale is indicator of psychological health. Self-actualizing person is autonomous, independent and free, but it does not mean alienation and loneliness. According to the "spontaneity" mean is $(13 / 11)$, high scores from students of psychology high scores indicate the confidence and trust to the world. Spontaneity is related to such values as freedom, naturalness, game, and ease without effort. In terms of "self-understanding" high average values were obtained in students of psychology and it indicates their sensitivity to human desires and needs. Lower scores are peculiar to people who oriented to the opinions of others. On a scale of "autosympathy" average values are the same for both groups (12/12). This suggests that students have low anxiety which is the natural basis of psychological health and integrity of the individual. On a scale of "contact" the highest average scores had been received (15/15). On a scale of "contact" the highest average scores $(15 / 15)$ had been received. This testifies the sociability of individual, ability to establish strong and friendly relations with others. On a scale of "flexibility in communication" mean is (14/15), the data shows a lack of social stereotypes. Students can easily communicate, consider themselves attractive and interesting. The results of study of individuals' of motivational structure showed information that characterizes the work and daily orientation of the student. Comparative characteristics of the data presented in Table 2 .

Table 2. Average values for work and daily orientation of the student's personality

\begin{tabular}{|c|c|c|c|c|c|}
\hline \multirow{2}{*}{$\begin{array}{c}\text { Sca- } \\
\text { le }\end{array}$} & \multicolumn{2}{|c|}{$\operatorname{GP}(\mathrm{n}=30)$} & \multicolumn{2}{|c|}{$\mathrm{FM}(\mathrm{n}=30)$} & $\mathrm{U}$ \\
\cline { 2 - 6 } & $\mathrm{M} \pm \mathrm{m}$ & $\sigma$ & $\mathrm{M} \pm \mathrm{m}$ & $\sigma$ & \\
\hline 1 & $\begin{array}{c}22,5 \pm \\
0,23\end{array}$ & 1,78 & $\begin{array}{c}24,38 \pm \\
0,27\end{array}$ & 1,69 & 687 \\
\hline 2 & $\begin{array}{c}18,7 \pm \\
0,26\end{array}$ & 2,00 & $\begin{array}{c}21,90 \pm \\
0,45\end{array}$ & 2,84 & 949,5 \\
\hline
\end{tabular}

\begin{tabular}{|c|c|c|c|c|c|}
\hline 3 & $\begin{array}{c}19,2 \pm \\
0,32\end{array}$ & 2,46 & $\begin{array}{c}24,23 \pm \\
0,29\end{array}$ & 1,86 & 878,5 \\
\hline 4 & $\begin{array}{c}24,1 \pm \\
0,32\end{array}$ & 2,47 & $\begin{array}{c}21,20 \pm \\
0,36\end{array}$ & 2,29 & 769,5 \\
\hline 5 & $\begin{array}{c}18,0 \pm \\
0,20\end{array}$ & 1,58 & $\begin{array}{c}23,43 \pm \\
0,25\end{array}$ & 1,55 & 807,5 \\
\hline 6 & $\begin{array}{c}20,3 \pm \\
0,24\end{array}$ & 1,86 & $\begin{array}{c}21,65 \pm \\
0,33\end{array}$ & 2,11 & 565 \\
\hline 7 & $\begin{array}{c}20,7 \pm \\
0,22\end{array}$ & 1,72 & $\begin{array}{c}23,33 \pm \\
0,22\end{array}$ & 1,37 & 987 \\
\hline
\end{tabular}

Note: GP - a group of psychologists; GM - a group of managers; $\mathrm{M} \pm \mathrm{m}$ - mean \pm standard deviation; $\sigma$ median; U - the Mann-Whitney test; 1 - life support; 2 - comfort; 3 - social status; 4 - communication; 5 overall activity; 6 - creative activity; 7 - social utility.

Daily motivational orientation consists of the first four indicators 1-4. Motivational profile of psychologists group on a scale "life support" showed the mean value of (22.5) whereas managers got (24.38). Received ratio expresses their relation to material goods and health. Students recognize that the attitude to work is a necessary achievement, which demonstrates a high level of motivation. The results in terms of "comfort" are following (18.7/21.90). Examined students spoken in favor of conflict avoidance. Students in both groups wish leisure and entertainment, and want to work in a good friendly team. Average values on a scale of "social status" were as follows - (19.2/24.23): Group of managers believes that it is necessary to work hard to get a good job, strive for a healthy careerism, and expressed a desire to have authority and respect with others. By the fourth scale "communication" students showed a high level of communication (24.1/21.2), the desire to have a lot of friends, expressed optimism and aspiration to have a good family. Working motivational orientation was determined according to the 5-6 scale. Data on the scale of "total activity" (18.0/23.43) indicate pragmatism of students of economics against the motivation of gaining knowledge, wealth and learning. This is reflected in the desire to obtain a good job, position, and desire to show their organizational skills. The sixth scale "creative activity" (20.3/21.65) results express the following trends: the desire to invent a new, constantly improve, to have a job of a creative nature, strive for success and achievements. All these trends are noticeable in both groups. By the sixth scale "social utility" (20.7/23.33), the results indicate the desire to engage in work that will benefit all. It should be noted that the examinees of both groups wanted to acquire respect, recognition and gratitude of others.

At the third stage of the study to diagnose achievement motivation the resulting tendency of motivation was measured according to the Mehrabian's test-questionnaire. That is the degree of predominance of one of these motives - striving to 
achieve or avoidance of failure. High indicators on the test indicate that the desire to achieve success more pronounced than the avoidance of failure, low on the contrary.

Information which was obtained during the study indicates the predominance of a high level of achievement motivation in both groups. The results show that subjects with an average level of motivation have a stable level of interest in life. Respondents with poor motivation prefer law or, conversely, too high risk. The higher the person's motivation to succeed - the goal, the lower the willingness to take risk. At the same motivation to success affects the hope of success: with a strong motivation to succeed hopes for success are usually more modest than for weak motivation to succeed. Those who are highly motivated to succeed and have a high willingness to take risks, less likely to get into accidents than those who have a high willingness to take risks, but the high motivation of avoiding failures (protection). Conversely, when a person has a high motivation for avoiding failures (protection), it prevents the motive to success - achieving the goal.

During the study the following data was obtained (Table 3):

Table 3. Levels of achievement motivation among students

\begin{tabular}{|c|c|c|c|c|}
\hline \multirow{2}{*}{ Level } & \multicolumn{2}{|c|}{ GP } & \multicolumn{2}{c|}{ GM } \\
\cline { 2 - 5 } & Qty & $\%$ & Qty & $\%$ \\
\hline low & 3 & $10 \%$ & 2 & $7 \%$ \\
\hline average & 15 & $50 \%$ & 13 & $43 \%$ \\
\hline high & 12 & $40 \%$ & 15 & $50 \%$ \\
\hline
\end{tabular}

Note: GP - a group of psychologists; GM - a group of managers.

The data obtained indicate that among students of psychology indicators are following: a low level of achievement motivation - $10 \%$, average $50 \%$ level of motivation and a high level of achievement motivation - 40\%. Results of the study group of managers on achievement motivation gave the following results - low level of achievement motivation $-7 \%$, the average level of motivation $43 \%$ and a high level of motivation to achieve $50 \%$ (Figure 1).

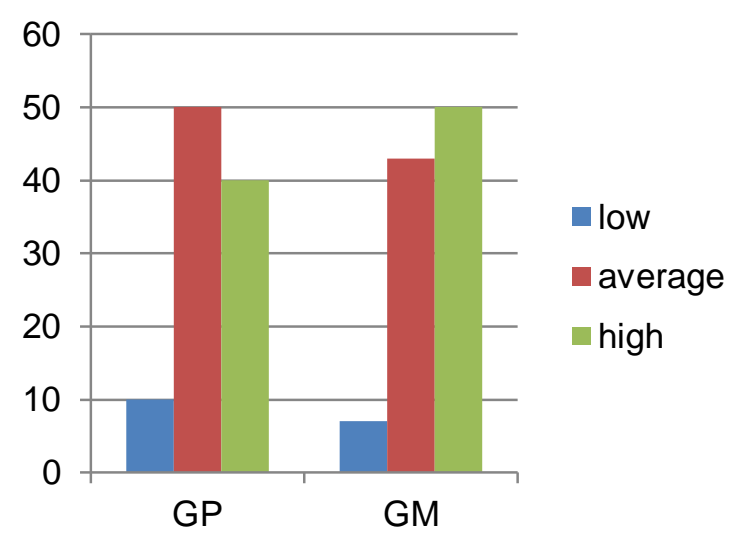

Figure 1. Levels of achievement motivation among students

\section{Conclusion}

The following conclusions were drawn in the result of this study:

1. Study of achievement motivation, its level and peculiarities is important in terms of identifying potential opportunities for the development of personality.

2. In the student age achievement motivation generates and promotes harmonious development of human personality.

3. Daily sphere plays a leading role in supporting the formation of motivational orientation and work sphere - in developing motivational orientation.

4. Study of achievement motivation and personality characteristics of students revealed aspiration to increase motivational orientation. Students with an average level of motivation have a stable high level of knowledge and cognitive interest.

5 . The higher person's motivation to succeed - the goal, the lower the willingness to take risks. Those who are highly motivated to succeed and have a high willingness to take risks, less likely to get into accidents than those who have a high willingness to take risks, but the high motivation of avoiding failures (protection). Conversely, when a person has a high motivation for avoiding failures (protection), it prevents the motive to success - achieving the goal.

6. Modern students who have chosen the humanitarian and economic professions are more likely to believe in themselves and in their abilities, they also believe in honest, sincere and mutually beneficial relationships with other people. Have a good tendency to self-actualization.

\section{References}

[1] Deci E.L., Ryan R.M., "The "what" and "why" of goal pursuits: Human need and the self determination of behavior", Psychological Inquiry, 2000, pp. 227-268.

[2] Heckhausen H., Motivation and Action 2nd Edition, Pedagogika, Moscow, 1986. 
[3] Murray H.A. Toward a classification of interaction, Mass: Harvard University Press, Cambridge, 1951.

[4] McClelland D., Motivation of the person, St. Petersburg, 2007.

[5] Ushakov D.V. Intelligence: Structural and dynamic theory, Publishing house "Psychology Institute of the Russian Academy of Sciences", Moscow, 2003, p.264.

[6] Burlachuk L.F., Korzhokova E.U., Psychology of life situations, Russian pedagogical agency, Moscow, 1998.

[7] Magomed-Eminov M.S. Achievement motivation: structure and mechanisms: Abstract of the thesis, prepared by candidate of psychological sciences. - Moscow, 1987 $20 \mathrm{p}$.

[8] Maslow A., The Farthest Reaches of Human Nature, Vlados, Moscow, 2007.

[9] Fetiskin N.P., V.V. Kozlov, G.M. Manuilov Sociopsychological diagnosis of personality development and small groups, Moscow, 2009.

[10] Milman V.E. The method of studying the motivational sphere of the person, Moscow, 1990. 